\title{
Prof. Fanish Mani Tripathi-A Tribute to The Eternal Teacher
}

\author{
Sudhir Singh ${ }^{1, \odot}$ \\ 1Department of Plastic Surgery, Getwell Hospital, Varanasi,
Uttar Pradesh, India
}

Indian J Plast Surg:2020;53:321-323

Born in pre-independent India on July 6, 1942, in the small village of Khoraram in the state of Uttar Pradesh. Fanish Mani Tripathi belonged to a family of prosperous landowners ( - Fig. 1).

His illustrious career of many firsts started when he graduated in the first batch of biology from Gorakhpur University and began his journey in medicine when he joined the very first batch of MBBS at the Institute of Medical Sciences, Banaras Hindu University (IMS BHU), Varanasi, in 1960.

Following graduation, he decided to train as a surgeon, and under the guidance of the renowned surgeon and Padma Shri Awardee Dr. N.N. Khanna (-Fig. 2), he blossomed as a surgeon. It was perhaps not surprising that in those days of rigorous training and exacting standards, Dr. Tripathi was the only successful candidate from a batch of six students in the MS exit examination!

At this juncture, he decided to pursue a career in a surgical discipline which owed its origins to this land, but as opposed to the modern version, plastic surgery at that point in time was still in a nascent stage not just at the institute but in the entire country. This speciality had recently gained stature and impetus under the dynamic leadership of the famous plastic surgeon Dr. J.K. Sinha who established the Plastic Surgery Division at IMS BHU. Dr. Tripathi completed his M.Ch from the new division, was appointed lecturer in the faculty, and by dint of his talent and hard work, he rose up the hierarchy quickly. In the following four decades of his illustrious career, he went on to establish and nurture a fullfledged department from this division. It is a testament to his pioneering work that during his tenure as head, the department and all the qualifications awarded by it won academic recognition from the Medical Council of India (MCI).

Not content with this, he ventured further and went on to learn microsurgery, which at that time was a fledgling subspecialty, from Dr. Bruce Bailey at Stoke Mandeville Hospital, in England. Being the visionary that he was, Prof. Tripathi
Address for correspondence Dr. Sudhir Singh, MBBS, MS, MCh, FICS, FIAMS, Department of Plastic Surgery, Getwell Hospital, Varanasi, UP 221005, India (e-mail: s.sulekha@gmail.com).

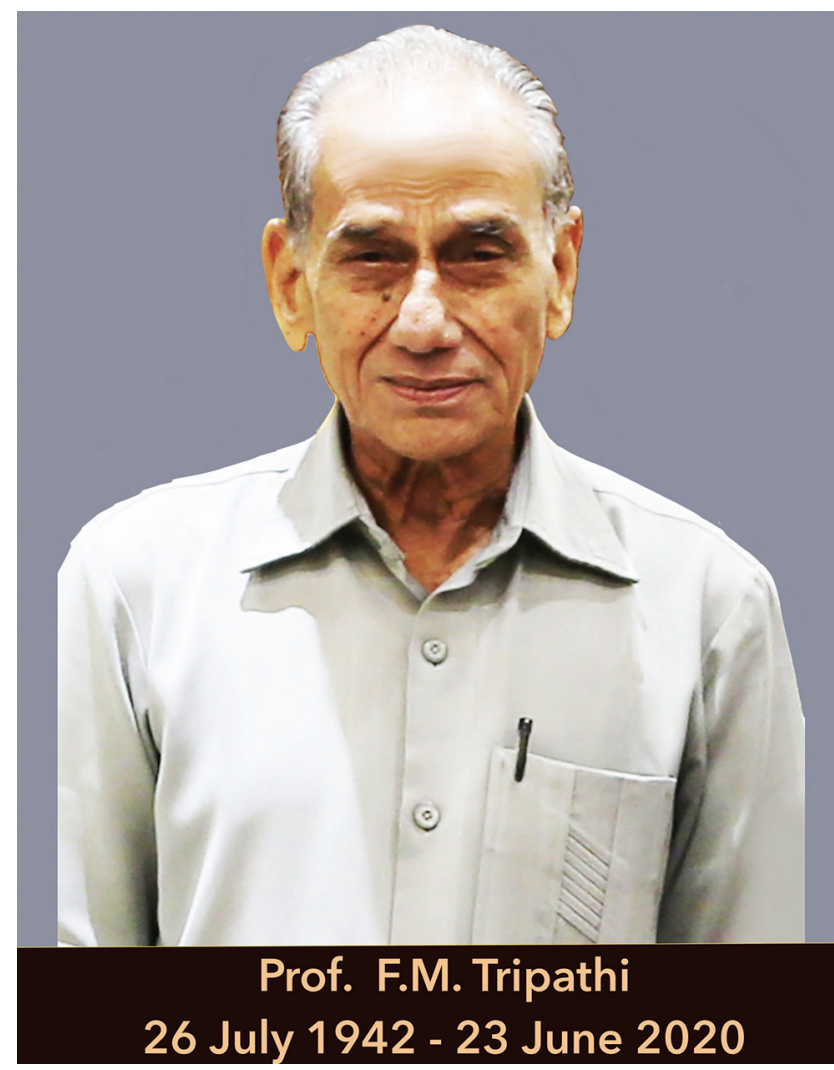

Fig. 1 Prof. F. M. Tripathi-- The Eternal Teacher.

could anticipate the potential demand for plastic surgery as well as for a subspecialty (-Fig. 1) like microsurgery among a rapidly growing Indian population. On his return from England, this foresight translated into him establishing the Hand and Microsurgery Division within the Department of Plastic and Reconstructive Surgery at IMS BHU, in order to train budding microsurgeons at the institute. An experimental microsurgery laboratory was formed in the department to published online

November 30, 2020
DOI https://doi.org/

10.1055/s-0040-1719207 ISSN 0970-0358. (c) 2020. Association of Plastic Surgeons of India.

This is an open access article published by Thieme under the terms of the Creative Commons Attribution-NonDerivative-NonCommercial-License, permitting copying and reproduction so long as the original work is given appropriate credit. Contents may not be used for commercial purposes, or adapted, remixed, transformed or built upon. (https://creativecommons.org/licenses/by-nc-nd/4.0/).

Thieme Medical and Scientific Publishers Pvt. Ltd. A-12, 2nd Floor, Sector 2, Noida-201301 UP, India 


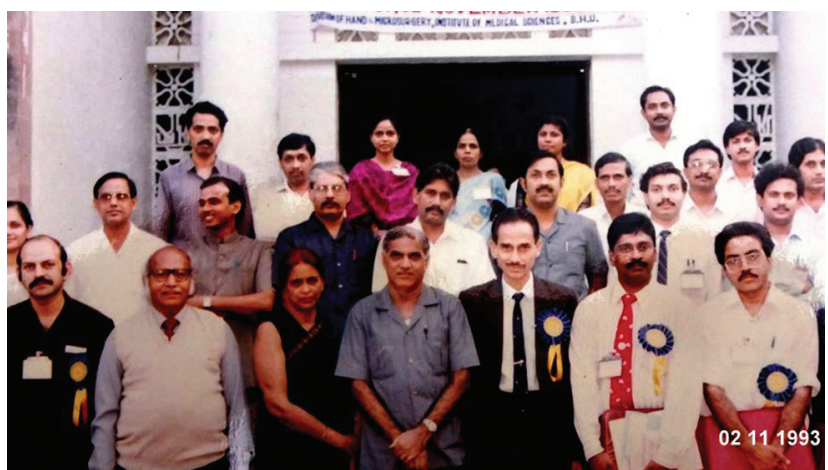

Fig. 2 Prof. F.M. Tripathi with his Guru Padam Shri Prof. N.N. Khanna.

train M.Ch. students. This was a bold and significant initiative in the eighties when India barely had a few microvascular training laboratories to train young plastic surgeons.

His special interest and research in lymphoedema took him to the Polish Academy of Sciences, Warsaw, where he studied various areas of lymphology. This led to the genesis of a lymphoedema clinic at IMS BHU in collaboration with the scientists of the Polish Academy, to address the needs of a large number of patients with lymphoedema. He forged a lasting and mutually beneficial friendship with Prof. Waldemar Olszewski, a vascular surgeon in Warsaw, Poland (-Fig. 3). This collaboration led to several roundtable conferences, seminars, and exchange visits. An Indo-Polish collaborative group, which is active to date, was established which saw a continuous exchange of research ideas and data.

Prof. Tripathi is renowned for his several seminal contributions in the fields of lymphology, peripheral nerve surgery, microsurgery and brachial plexus injury, all of which will remain part of his valuable legacy.

He saw the future of plastic surgery branching into several subspecializations and disciplines. Recognizing the importance of close cooperation and interaction, he strove to encourage all the subspecialties of plastic surgery, including lymphology, peripheral nerve surgery and microsurgery in his department and give them equal importance. Driven as he was by academic excellence, his tenure was marked by regular seminars, workshops, conferences in all the subspecialties. He himself attended every academic meeting possible and hardly missed a single APSICON, our annual national conference.

He retired as Professor and Head of the Department of Plastic Surgery, IMS, BHU, Varanasi in 2004. Subsequently, he was associated with the Universal College of Medical Sciences, Bhairawaha, Nepal, for the next 5 years. He was by nature helpful and even after his superannuation, he was always available for any consultation or advice to faculty, students, and administrators from institutions around the country. His wisdom guided many journeys and enriched many lives.

\section{Memberships and Affiliations}

In addition to his academic positions, Prof. Tripathi was also associated with numerous academic bodies. He was the

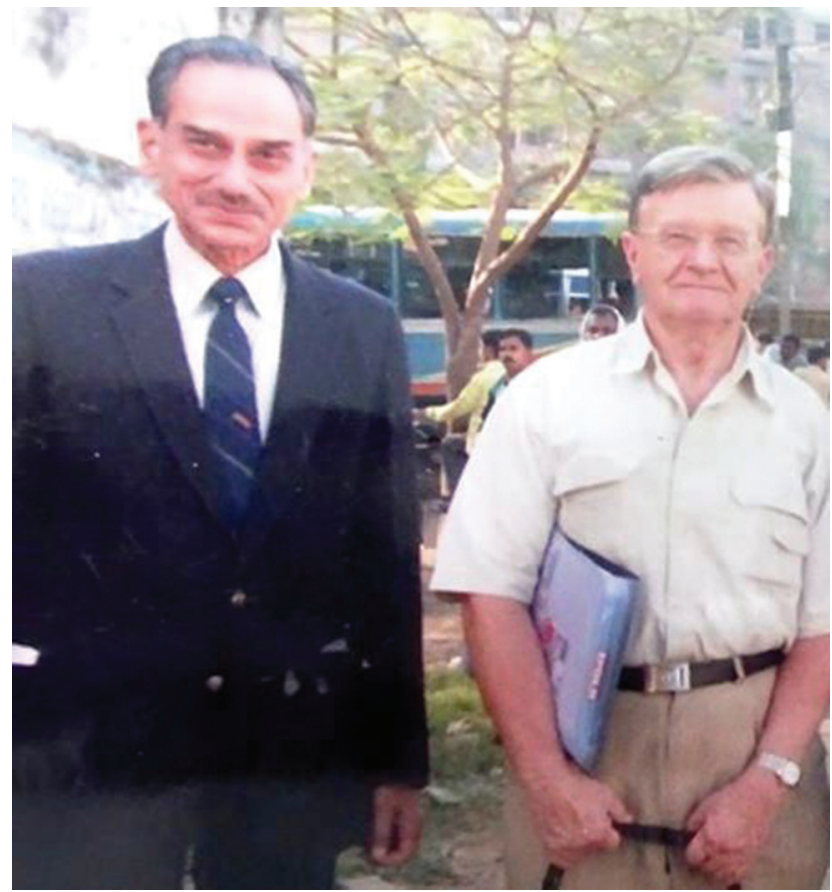

Fig. 3 Prof. F.M. Tripathi with Prof. Waldemar Olszewski.

founder president of the Indian Association for Peripheral Nerve Surgery (IAPNS), Indo Nepal Association for Peripheral Nerve and Lymphology Surgery, and the Indian National Society of Lymphology. He served as the President of the BHU branch of the Indian Medical Association (IMA) from 1996 to 1997.

\section{Awards and Citations}

In the course of a long and distinguished career, Prof F. M. Tripathi was the recipient of several awards and recognitions. The major ones among them are as follows:

Lifetime Achievement Award at the UP-UK Annual Conference of APSI in 2019.

Lifetime Achievement Award at the APSICON national meet in Bhubaneswar in 2019.

Ethicon Travelling Fellowship from APSI.

Commonwealth Medical Fellowship, United Kingdom, to learn hand microsurgery and head and neck surgery.

Indian National Science Academy Award (twice) to visit Polish Academy of Science, Warsaw, to learn various areas of lymphology.

A prolific researcher, he published a large number of scientific papers in various national and international journals of repute and supervised more than three dozen research theses for M.S. and M.Ch students and three theses for Ph.D. scholars in collaboration with various departments of IMS.

Throughout his career, he was actively involved in administrative affairs pertaining to his field, apart from organizing various workshops and conferences at both the national and international level.

In what could be termed as the culmination of his efforts to promote and encourage the areas in plastic surgery which 
he was fond of, his dream project, the Prof. K N Udupa Memorial Symposium on Peripheral Nerve Surgery, was conducted at the Institute of Medical Sciences, BHU, on the occasion of the institute's diamond jubilee in 2020. In a remarkable coincidence, the venue was the same lecture theater in the old building where he himself was a young student decades earlier! It was attended by almost all his close colleagues, students, admirers, and followers from all parts of the country. The occasion also marked the holding of the silver jubilee symposium of the IAPNS.

He was a teacher throughout his life and in a sense never "retired." Even in the last few weeks, he had begun to plan post COVID-19 conferences on lymphology, oculoplastic surgery, and hand and microsurgery with the help of students. Countless students of his are carrying on the good work across the country in the same spirit of selfless service imbibed from their guru.

To me, his passing is a personal loss.

I owe my knowledge of plastic surgery to him. I was lucky that he persuaded me to pursue this field, when I had my mind fixed in another direction. He treated all his students like a part of his family, and I was no exception. I recall that at every stage of my career, he would demand more of me, pushing my limits, encouraging me to keep on learning, mastering new techniques, keeping a global outlook and observing every development.

He was very humble, and despite his prosperous background, he was always sensitive to the needs and problems of common people. At an interpersonal level, he spread a lot of cheer and optimism and was always a source of hope to those around him.

Rooted as he was to this land, he nursed a deep fondness for folklore and culture and all things Indian. He loved music forms like "Birha," entertainment forms like "Nautanki" and found time for traditional classical music. Like many of his students, I too developed a fondness for these things as my bond with my guru grew stronger.

Blessed with a life of good health, he suffered a very brief illness and suddenly passed away unfortunately on June 23 , 2020 , on the auspicious day of "Rathyatra," leaving all of us in shock and grief towards the end. He is survived by his wife, two sons, and two grandchildren. His passing marks the end of an era and will leave an irreplaceable void in our fraternity.

He leaves behind an enduring legacy of using the power of medical knowledge and selfless service to bring hope and relief from disease, deformity, and trauma to millions living in pain and suffering.

May his soul find eternal peace.

\section{Funding}

None.

\section{Conflicts of Interest}

None declared. 